\title{
GEOGAME ON THE PEAT: DESIGNING EFFECTIVE GAMEPLAY IN GEOGAMES APP FOR HAZE MITIGATION
}

\author{
Trias Aditya ${ }^{1}$, Dany Laksono ${ }^{1}$ \\ ${ }^{1}$ Department of Geodetic Engineering, Universitas Gadjah Mada, Yogyakarta 55281 - (triasaditya, danylaksono)@ugm.ac.id
}

Commission IV, WG IV/9

This paper is submitted for the Workshop/Theme session on Virtual \& Augmented Reality: Technology, Design \& Human Factors, organized by ISPRS Working Group IV/9.

KEY WORDS: Haze mitigation, Peatland fire, User Studies, Gameplay, Geogame

\begin{abstract}
:
The Southeast Asian Haze in 2014 and 2015 is the worst transboundary haze episodes recorded to date. The haze mainly originated from burning of biomass material in peatland area, caused major health problems and economic losses. Peat forest conversion to forest and agriculture industry by utilizing drainage canals is one of main fire drivers that need to be restored, while conflicts on land and livelihood further adding complexity on the issue. Water and peatland management are among the key activities for reducing the peat fire risk and for eliminating the transboundary haze problems. Geospatial data have been collected in peatland are as in Indonesia to support hydrological restoration plans to prevent drying of peat biomasses. Aside from satellite and UAV data, crowdsourcing could also be conducted by engaging residents in collecting spatial data on peat environment while at the same time raising awareness on peatland management and peat fire prevention. This paper elaborates our findings in developing a Geogame App for mitigating haze in peatland area. The study area is situated in Padang Island, Riau, Indonesia. The gamification was implemented as a location-based, augmented reality adventure game. The storyline revolves around peat-related theme, with game elements represent different aspects of peatland management. The game incorporates real-world data as a game element, which also serves as a platform for collecting data around the users. Game mockup and use case scenario are provided to model the spatial data collected through the game for decision makers related to peat fire management.
\end{abstract}

\section{INTRODUCTION}

\subsection{Peat Haze and Wildfire}

The haze from wildfire has become a prolonged issue to mainly firing of drained peatland, especially in Indonesia where about 20 million Ha of peatland is situated (Page, Banks, and Rieley 2007). The haze in 2014 and 2015 was recorded as the worst and longest case of the wildfire in South East Asia. Peat forest conversion to forest and agriculture industry by utilizing drainage canals is identified as one of the main drivers of these wildfires (Susanti et al. 2017). The drained peatland for agriculture and forestry industry has created massive opportunities for fast profit investments but at the same time it caused worsened environmental degradation as it made the peat dried and flammable. The problem started back in late 2000s when many forested peatlands were converted to forest industry. Besides reducing massive natural peat forest, the industry also made canals without paying attention to hydrological reserves of the peatland landscape unit. As the result the water inside the peat dome dried, causing the peat dryness known as "sponge effect" (Andriesse J. P 1988). This in turn caused peatland subsidence and make the peatland more vulnerable to fire. Big fires in huge areas of drained peatland will cause massive haze crisis caused by winds blowing smoke.

Such case is occurred in Padang Island, situated in Riau, Indonesia, which is one of the largest peat islands in Indonesia. Susanti et al. (2017) identifies that the main driver for the severe environmental deterioration of peatland area in Padang Island is the introduction of plant species such as rubber and acacia. Fulfilling the forest industry demand, massive peatland area were converted into acacia and rubber plantation. These species accelerated the drying peatland since it needs dry soil for its growth, aside from its high rate of transpiration. The problems of land conflict and livelihood involving stakeholders and community in peatland areas added the complexity in the deterioration of peatland. This urges the need for environmental management of peatland area and restoration of the hydrological condition to prevent further drying of peatland and reduce the chance of peat wildfire. One of efforts is to raise awareness of the community and stakeholders on how to maintain the hydrological state of peatland, which could be obtained by educating the younger age of residents living in peatland area.

\subsection{Augmented Reality Gamification}

Gamification could be interpreted as a way of presenting complex and serious ideas into a less intricate concept. Nicholson (2015) elaborate models of gamification where the game could be designed to get the players to engage in a context. Players of such game could be directed into a long-term change in their realworld behavior by selecting the appropriate model of userreward. Thus, gamification could act as an education platform which conveys messages, given proper system of rewardpunishment connected to real-world themes. For example, a theme on disaster and safety education could be conveyed through a game (Wahyudin and Hasegawa 2017).

The basic tenet of gamification is that people play not because they personally interested in some kind of objective, but because they want to be entertained (von Ahn and Dabbish 2008). Thus, a game which is fun to play could be used as a tool to convey messages and to collect data. Examples of such games could be 
found for instances in Kuo et al. (2009) and Matyas (2007). In the latter, GPS coordinates were generated through locationbased games. While children play entertaining game by going around the town, GPS data were collected and further analyzed for other purposes.

Another potential means for gamification is augmented reality. The advancement in mobile devices opens up new possibilities for utilization of augmented reality (Noor et al. 2015). Augmented reality games could be designed with the purpose of conveying messages or collecting data. Additional purposes could be included in a location-based augmented reality games, namely educating the players and collecting geospatial data at the same time. In order to create users engagement and active participation, 3D augmented reality games need to have useful stories to convey the intended messages for raising the awareness and for facilitating data collection at once. Storytelling can explain complex relationships of geospatial data while users experiencing interaction with the real world offered through 3D geo visualization. It offers a wide range of possible combinations between narrative elements (i.e. setting, atmosphere, points of view, and character) and user engagement (i.e. attraction, affection, interaction, comeback) to convey the same story in many different ways (Thöny et al. 2018). Applying games technology to geo-virtual environment can create more interactive and realistic learning environments that offer "high levels of engagement and knowledge formation" for non-expert users (Germanchis et al. 2004).

This paper discusses our finding in designing a geolocation-based augmented reality game. The game is designed to present basic concepts of peatland management aimed at educating the residents of peatland area. The game could also be used to gather peatland-related data such as canal and canal blocking which could be used for further analysis on hydrological problems in peatland area.

\section{GAMIFICATION DESIGN}

\subsection{Study area}

This paper elaborates our findings in developing a Geogame App for mitigating haze in a peatland area. Padang Island in Riau, Indonesia is selected as the study area for its relatively contained peatland area with various problems related to peatland management and livelihood of the residents. Previously, geospatial data acquisition has been conducted in the area in order to analyze the peatland hydrological problems and to support livelihood revitalization (Susanti et al. 2017). Among the data are high-resolution LiDAR data and aerial photo used to model hydrological state of the peatland and obtain detailed land cover map in Padang Island (see Figure 1).

The geospatial data previously collected through LiDAR and aerial photo could be used for conducting analysis on a specific time frame only. However, the factors involved in peatland hydrology in Padang Island are quite complex and acted dynamically against each other. Thus, a near-real time geospatial data is needed in order to act as soon as its needed. Also, the nature of peatland hydrological data required local knowledge of residents living in the area, such as local activities on development of new canals or land clearing activities. Land clearing activities with fire could still be found in the field in recent years. It is expected that involving residents in crowdsourcing geospatial data could contribute in providing more accurate data related to peatland management and haze mitigation in a timely manner. Padang Island has a very long history on peat fires. As presented in Figure 2, the fire hotspots from 2004 up to 2015 have massively occurred across village areas.

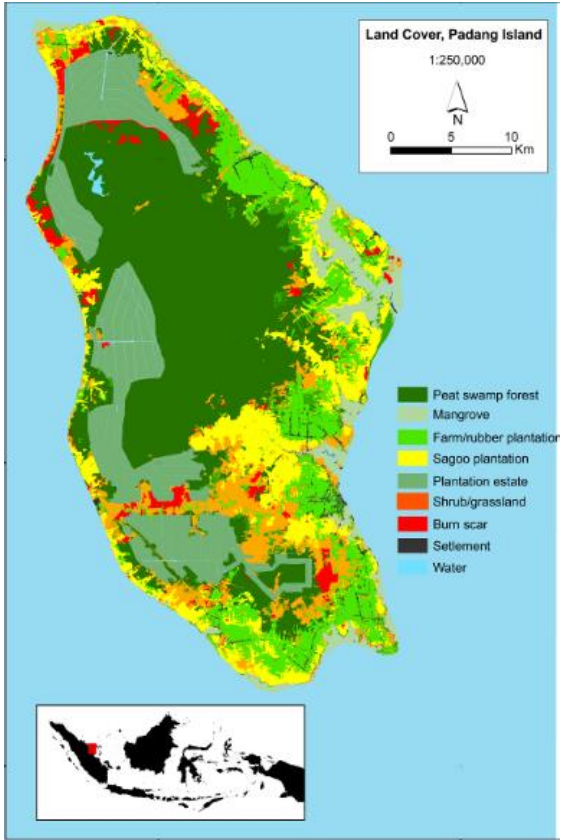

Figure 1. Study Area in Padang Island, Riau

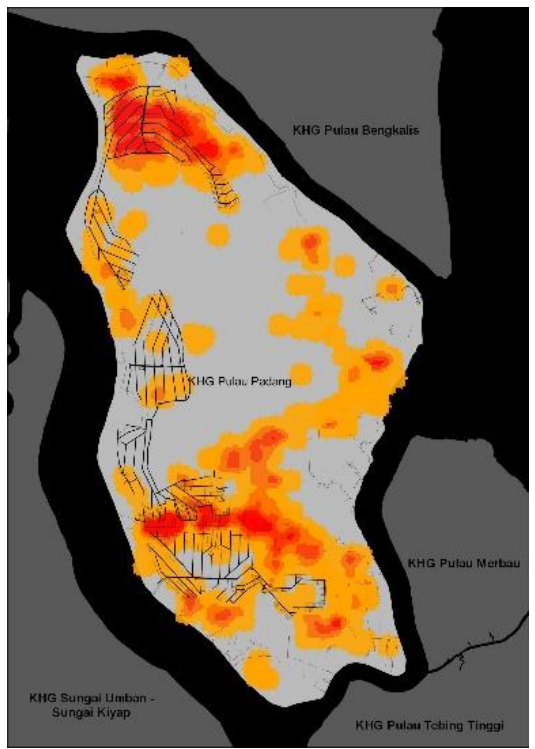

Figure 2. Heatmap of hotspots from 2004-2015 in Padang Island

The applicability of the game is intended for nationwide uses as there are many more peat islands in the country that need to be protected from fire and haze. The targeted users are young residents of local population frequently affected by peat fire. The purposes of game design are 1) to educate the users on peatland management, 2) to crowdsource peatland-related data through location-based games, 3 ) to provide a platform for early detection and hotspot validation. During the gameplay design, some questions were used as guidelines. These include: (1) evaluation on age limitations; (2) gameplay patterns and characterization; (3) the intended messages to convey to users; (4) expected time to play the game; (5) user competition and user personalization design; (6) user analytics on game playing; (7) game continuation and follow-up. 
User scenario was initially developed based upon those questions. User scenario document was created to equip the gameplay design with possible user activities, game rules, user rewards and other information in regard to possible messages to convey about peatland management. The user scenario also captures user interaction scenario in regard to AR camera capture as well as hotspot validation.

\subsection{Gameplay design}

We designed a game to serve the abovementioned purposes, which is to educate the children and collect information in peatland area. The game, called "The Game of Peat" is designed as an augmented reality game based on real-world location. Basic gameplay includes a map with augmented reality mode where players could interact with virtual objects such as plants, items, coins, and inventory bags. The items are spread in various location, while the players need to collect them by visiting the location at an approximate location. The item could then be collected using augmented reality camera.

Using guideline questions specified in 2.1., a field visit to interview village leaders and to understand challenges of fire management from residents' perspectives based on their experiences was done in Padang Island. The information collected was used to develop possible game mechanics and narrative elements suitable for young residents living in peatland areas. In detail, the gameplays of "The Game of Peat" are as follows:

1. At the beginning of the game, the player is given a plant seed. They need to put the seed in a specific location to continue playing

2. The objective is to keep the plant alive, and the players should defend the plant against fire, drought, pests, flood, etc.

3. In order to keep the plant alive, players should collect various items such as pail for watering the plant, fire extinguisher for putting off fire, etc. These items are collected by walking near by the location and activating AR (augmented reality) camera to 'catch' them. Collected items are stored in the inventory.

4. There are various kinds of plants, and players should collect coins in order to buy new plants. Different kinds of plants required a different tool to keep them alive

5. Coins are collected by walking through them in realworld locations, without the need to activate AR Camera

6. As the level rises, difficulty grows harder, i.e. more pests, flood inundation, and so on.

7. Each time a new plant is collected, players will receive a new kind of task. Experience points will be obtained by finishing the task.

8. The task is time constrained. Therefore, if the player failed to finish a task before a given time, the plant will decay and subsequently dried or burned.

9. More coins could be obtained when players submit pictures of canals, canal blocking, hotspot field validation or other real-world data related to peatland hydrology through AR Camera.

10. Punishment, in form of emptying inventory, reducing coins or reducing experience point, will be executed if the player loss a plant or submitting false reports.

Based on the gameplay design, we specify game elements, which are plants, items ('collectibles'), coins, map and inventory bag. Players should be walking around the area while utilizing augmented reality camera in order to collect or put items.
Gameplay and game elements are designed to be simple enough for children aged 13-16 years old. However, the age limitation is not restricted, and basically everyone could play the game and grasp the idea of peatland management.

\subsection{Gamification strategies}

The purpose of educating the players are executed as a gamification strategy which is implemented into the gameplay. Some elements of peatland management were included into the game so as to engage the player in a real-world situation in every peatland area. Table 1 shows gamification strategies for different peatland related issues.

\begin{tabular}{cc}
\hline $\begin{array}{c}\text { Peatland management } \\
\text { education }\end{array}$ & Game mechanics \\
\hline $\begin{array}{c}\text { Different types of plants } \\
\text { grow differently in a } \\
\text { peatland area. Some kinds } \\
\text { of plant are not suitable } \\
\text { for peatland area }\end{array}$ & $\begin{array}{c}\text { Different types of plants have } \\
\text { different time of decay. Plants } \\
\text { such as acacia decayed more } \\
\text { quickly and more often } \\
\text { causing peat wildfire }\end{array}$ \\
\hline $\begin{array}{c}\text { In order to keep the } \\
\text { peatland from fire, the } \\
\text { hydrological state needs to } \\
\text { be stable }\end{array}$ & $\begin{array}{c}\text { Players should collect water } \\
\text { jug from time to time in order } \\
\text { to keep the plant from dried or } \\
\text { eventually burned }\end{array}$ \\
\hline $\begin{array}{c}\text { Peatland fire spreads } \\
\text { quickly }\end{array}$ & $\begin{array}{c}\text { Fire consumed a plant far more } \\
\text { quickly compared to other } \\
\text { kinds attack (pests, flood, etc) }\end{array}$ \\
\hline $\begin{array}{c}\text { Introducing different kinds } \\
\text { of pests attacking peatland } \\
\text { native plants }\end{array}$ & $\begin{array}{c}\text { Different pests attacking } \\
\text { different plants }\end{array}$ \\
\hline $\begin{array}{c}\text { Canals and canal blocking } \\
\text { could be used to balance } \\
\text { water state in peatland } \\
\text { area }\end{array}$ & $\begin{array}{c}\text { Shovels and bricks, } \\
\text { respectively, are used to keep } \\
\text { the water level of plants } \\
\text { balanced and keep them from } \\
\text { fire }\end{array}$ \\
\hline Table 1. Some gamification strategies
\end{tabular}

Aside from the above strategies, specific elements of peatland related theme could be involved in various activities during the gameplay.

\section{GAME DESIGN IMPLEMENTATION}

\subsection{Game Software Architecture}

The design is implemented as an adventure, location-based augmented reality game on Android platform. The game is developed using Unity Game Engine, as well as Motive.io platform for gameplay design and Mapbox Unity SDK to provide custom basemap style, as well as providing real-world context to the game.

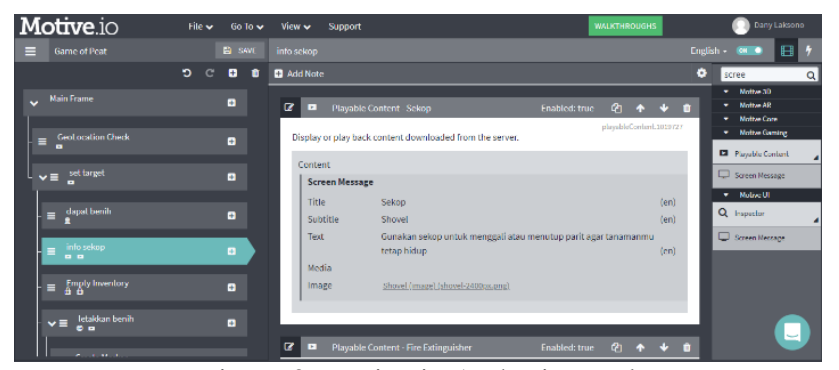

Figure 3. Motive.io Authoring tool

The Game of Peat was built on top of Motive.io AR-Explorer Unity template and compiled as Android APK using Unity 
internal compiler. Motive.io authoring tools (Figure 3) provided implementation of gameplay based on the design, as well as storing images and media needed in the game.

Motive IO authoring tools were used to build game elements as well as its interactions with the player. Game elements are core implementation of gameplay in The Game of Peat. Each game element represents a way to implement gamification strategies (See Table 2). For example, Acacia plant seed will be decayed or pest-invested more quickly compared to other types of seed. The plant seed variable is implemented using Motive IO enumerable parameters, which by itself correlated to other game elements such as number of coins.

\begin{tabular}{|c|c|c|}
\hline Categories & Elements/Items & Explanation \\
\hline Characters & $\begin{array}{l}\text { Kakek Gambut } \\
\text { ('grandpa } \\
\text { peat'), Petani } \\
\text { benih ('seed } \\
\text { farmer'), } \\
\text { penjual alat } \\
\text { ('shop clerk') }\end{array}$ & $\begin{array}{l}\text { Characters interact with } \\
\text { player by giving } \\
\text { instruction or clues, as } \\
\text { well as giving items to } \\
\text { player. Sometimes player } \\
\text { needs to exchange coins or } \\
\text { other items to obtain item } \\
\text { from a character }\end{array}$ \\
\hline Plant seeds & $\begin{array}{l}\text { Sagoo, Palm, } \\
\text { Acacia, Rubber, } \\
\text { other plants }\end{array}$ & $\begin{array}{l}\text { Different plant seed } \\
\text { requires different } \\
\text { treatment. The higher the } \\
\text { level of player, the harder } \\
\text { it gets to keep each plant } \\
\text { alive }\end{array}$ \\
\hline Disasters & $\begin{array}{l}\text { Fire, } \\
\text { Pests }\end{array}$ & $\begin{array}{l}\text { Disaster attacks in a timely } \\
\text { manner, given enough } \\
\text { conditions based on real- } \\
\text { world situation. For } \\
\text { example, flood occurred } \\
\text { one hour after a heavy rain. }\end{array}$ \\
\hline Collectibles & $\begin{array}{l}\text { Shovel, Bricks, } \\
\text { Water bucket, } \\
\text { Pest spray }\end{array}$ & $\begin{array}{l}\text { Player needs to obtain } \\
\text { collectibles in order to end } \\
\text { a disaster. In order to put } \\
\text { out fire, for example, } \\
\text { player needs to have at } \\
\text { least five buckets of water } \\
\text { beforehand. } \\
\text { Collectibles are placed } \\
\text { based on relative position } \\
\text { to the user as well as real } \\
\text { world conditions. The } \\
\text { items could be collected } \\
\text { only when the player is } \\
\text { near by their location. } \\
\text { Collection of items are } \\
\text { conducted using AR } \\
\text { Camera. }\end{array}$ \\
\hline Economics & $\begin{array}{l}\text { Coins, } \\
\text { Experience } \\
\text { Points (XP) }\end{array}$ & $\begin{array}{l}\text { Some collectibles are } \\
\text { obtained by exchanging } \\
\text { coins to a game character, } \\
\text { while experience points are } \\
\text { used to mark level of the } \\
\text { player }\end{array}$ \\
\hline
\end{tabular}

Table 2. Game Elements and Their Representations

\subsection{Game Flow}

The game starts by putting collectibles (such as coins, shovels, and water pails) situated around the player's current location. Aside from relative positioning based on user's current position, the locations of collectibles are parameterized based on realworld places, such as shops or schools. The first task is instructed by a game character, where the player needs to put a seed they obtained to a specific location. Further, the game progresses with the user finding new items and planting new seeds to new locations.

Plants will be decayed in a timely manner, which is instructed through Motive.io Authoring tools. Each kind of disaster trigger different timer for decaying or burning of the plant. Mechanism for plant being burned involves daylight condition, i.e., the fire only occurred during daytime or dawn (Figure 4). The timer stops when the player obtains sufficient items before the time runs out and bring the items to location of the plant. In such cases, player will obtain rewards (coins and experience points/XP) which could be used to obtain new plant seeds.

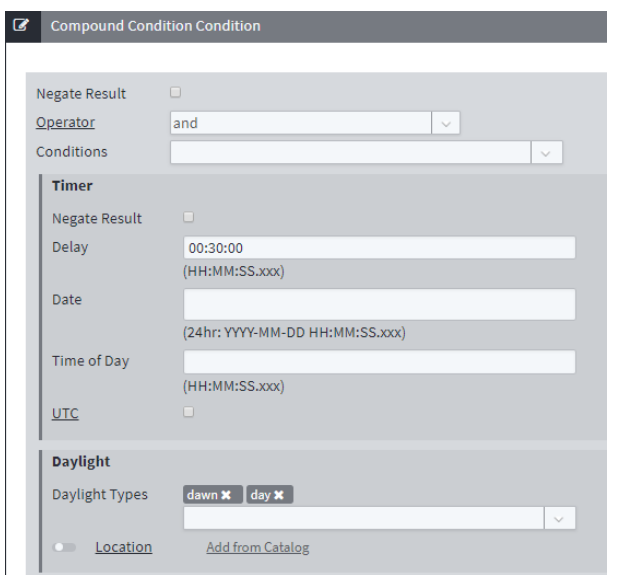

Figure 4: Timer and daylight condition to trigger disaster

The game concludes when the player obtains all kinds of plants, or all of the plants currently available died or being burned. User could also obtain XPs when reporting or taking pictures of realworld peatland related features such as newly built canals. However, punishments are applied when the user submitted a false report, which resulted in emptying the inventory or reducing coins. Game flow is illustrated in Figure 5.

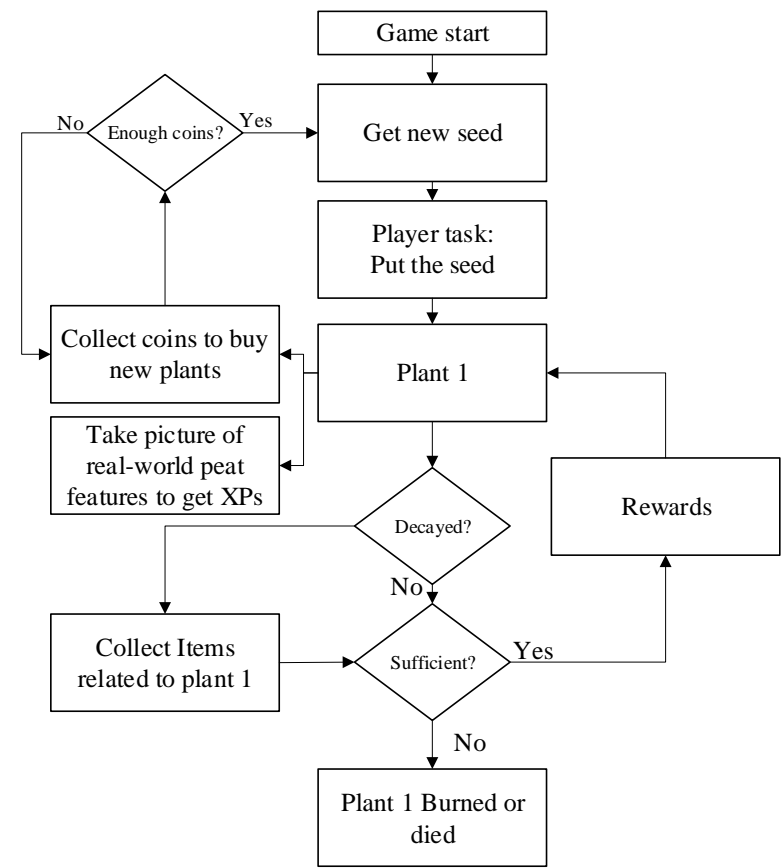

Figure 5. Game flow diagram 
In order to end a disaster and prevent the plant seed from dying, the player must perform a task. Each disaster requires different kinds of task. Some tasks are quite simple, such as collecting pest spray on pest-invested Sagoo seed. Other task is quite complex, such as building a canal blocking using shovel and bricks to prevent Acacia seed from being burned. Thus, to keep playing the game, the player needs to explore their surroundings to find collectibles (e.g., shovel or bricks) and coins (which are used to be exchanged with specific items). As more plant seeds are obtained, the game will grow more complex, and the player needs to utilize all their resources to keep their plant seeds alive.

\section{RESULT AND DISCUSSION}

\subsection{The Game of Peat}

Mockup of the Game of Peat is developed in Android platform using Motive.io under Unity Engine. The game should run in a minimum Android build version 5.0 (Lollipop). This build version was determined based upon feedback from local residents. Basic user interfaces of the game consist of main map menu with three buttons at the bottom of the screen. The buttons served as inventory, augmented reality camera and tasks, respectively (Figure 6).

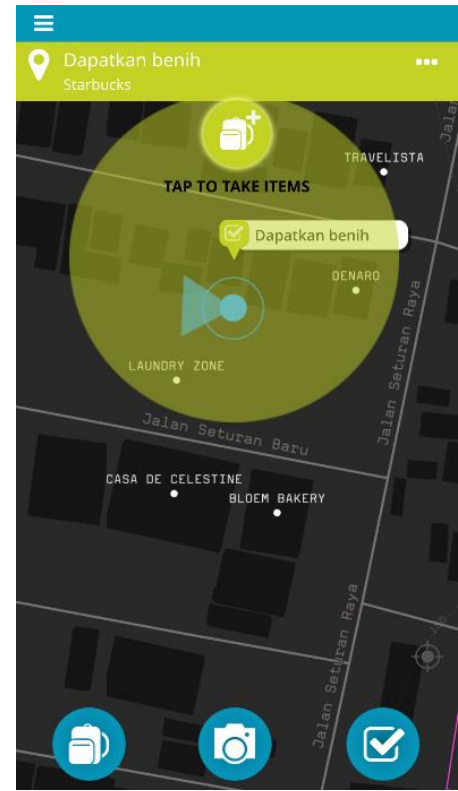

Figure 6. Basic user interfaces of The Game of Peat

In order to activate the AR Camera, or to put items in a designated location, the player should be situated nearby the location. A hint is displayed at the top of the screen when the player walks nearby an item or location for placing seeds. The inventory screen shows each item collected and their numbers, while the task screen shows every task that the user needs to complete before the time runs out.

\subsection{Discussion}

The Game of Peat, though in very early stages, incorporates education of peatland management issues, as well as crowdsourcing peatland-related data through the game. The gameplay implementing gamification design with the purpose to educate children on how to maintain peatland and preserve the water in peat area, as well as to keep peatland fire away.
By utilizing augmented reality camera (Figure 7) to collect items, players are encouraged to make observations on their surroundings. This in turn makes the players (in this case, children living in peatland area) to be more aware of issues related to peat and the outcomes of peatland mismanagement in their area.

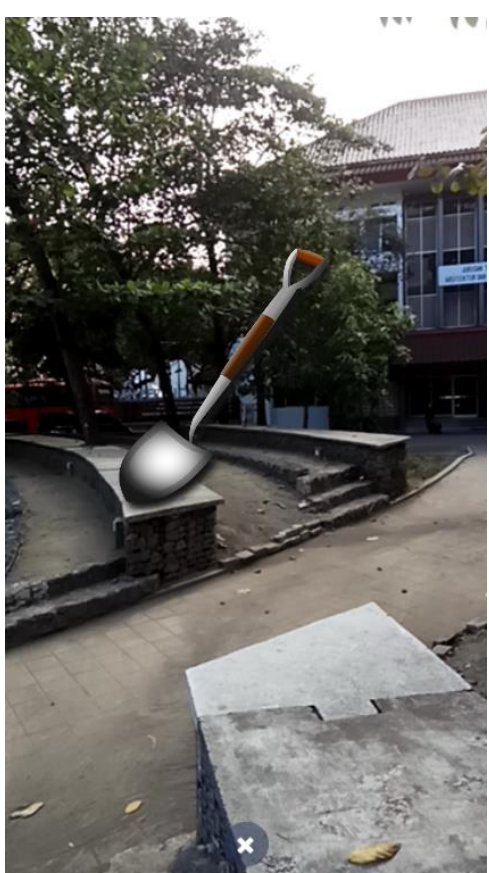

Figure 7. AR camera showing a collectible (a shovel)

The location-based element in the game is designed to convey messages and to collect data related to peatland area. The data collected from the players on the field such as canals development or hotspot validation can be extracted and plotted on the map to be used for decision makers' evaluation. Some feedback from local leaders were also gathered and processed during the design. This includes local stories and local leaders' experiences that inspire gameplay pattern and character. More screenshots showing the game interfaces are presented in Appendix (from Figure 8 to Figure 10). Further improvements could be made in relation to the development of the game, such as to utilize computer vision to identify real-world objects, a leaderboard for players and more game elements to educate more complex problems.

\section{CONCLUSION}

In designing the gameplay for a Geogame App for mitigating haze in peatland area, design questions were used as the guidelines to support the game design. The developed game, The Game of Peat, is designed to educate players on peatland management and to model the spatial data collected through the game for decision makers related to peat fire management. The game mechanics are focused to raise awareness on peatland protection and to educate young residents on the importance of peatland management. The gamification was implemented as a location-based, augmented reality adventure game. Game elements and game flow revolves around planting seeds and defending them to grow and not to decay. This is relevant with the game objective to support peat conservation and protection. The game incorporates possibilities to collect real-world data (such as location-based reports on new canals development or hotspot validation) around the users. 


\section{REFERENCES}

Ahn, Luis von, and Laura Dabbish. 2008. "Designing Games with a Purpose." Communications of the ACM 51 (8): 57. doi:10.1145/1378704.1378719.

Andriesse J. P. 1988. "Nature and Management of Tropical Peat Soils." FAO Soils Bulletin 59: 165.

Germanchis, T, C Pettit, W Cartwright, C Pettit, and W Cartwright. 2004. "Building a Three - Dimensional Geospatial Virtual Environment on Computer Gaming Technology Building a Three-Dimensional Geospatial Virtual Environment on Computer Gaming Technology." Journal of Spatial Science 49 (1): 89-95. doi:10.1080/14498596.2004.9635008.

Kuo, Yen-ling, Jong-Chuan Lee, Kai-yang Chiang, Rex Wang, Edward Shen, Cheng-wei Chan, and Jane Yung-jen Hsu. 2009. "Community-Based Game Design: Experiments on Social Games for Commonsense Data Collection." Proceedings of the ACM SIGKDD Workshop on Human Computation (HCOMP), 15-22. doi:10.1145/1600150.1600154.

Matyas, Sebastian. 2007. "Playful Geospatial Data Acquisition by Location-Based Gaming Communities." The International Journal of Virtual Reality 6 (3): 1-10.

Nicholson, Scott. 2015. "A Recipe for Meaningful Gamification." Gamification in Education and Business, 1-20. doi:10.1007/978-3-319-10208-5_1.

Noor, Nurtihah Mohamed, Fakhrul Hazman Yusoff, Rahmah Lob Yussof, and Marina Ismail. 2015. "The Potential Use of Augmented Reality in Gamification." Proceeding of International Conference on Computing and Informatics, no. 48: 159-67.

Page, Susan E, Christopher J Banks, and John O Rieley. 2007. "Tropical Peatlands: Distribution, Extent and Carbon Storage-Uncertainties and Knowledge Gaps." Peatlands International 2 (2): 26-27.

Susanti, Ari, Oka Karyanto, Agus Affianto, Ismail, Satyawan Pudyatmoko, Trias Aditya, Haerudin, and Hendra Arditya Nainggolan. 2017. "Understanding the Drivers and Impacts of Massive Peatland Drainage on Livelihood in Padang Island - Riau Province, Indonesia." In ICTA 2017 Sustainable Tropical Forestry: Forest Management, 1-12.

Thöny, Matthias, Raimund Schnürer, René Sieber, Lorenz Hurni, and Renato Pajarola. 2018. "Storytelling in Interactive 3D Geographic Visualization Systems." International Journal of Geo-Information $7 \quad$ (123): 14. doi:10.3390/ijgi7030123.

Wahyudin, Didin, and Shinobu Hasegawa. 2017. "The Role of Serious Games in Disaster and Safety Education: An Integrative Review," 180-90.

\section{APPENDIX}

Some of the screenshots of The Game of Peat are presented in Figure 8 to Figure 10.

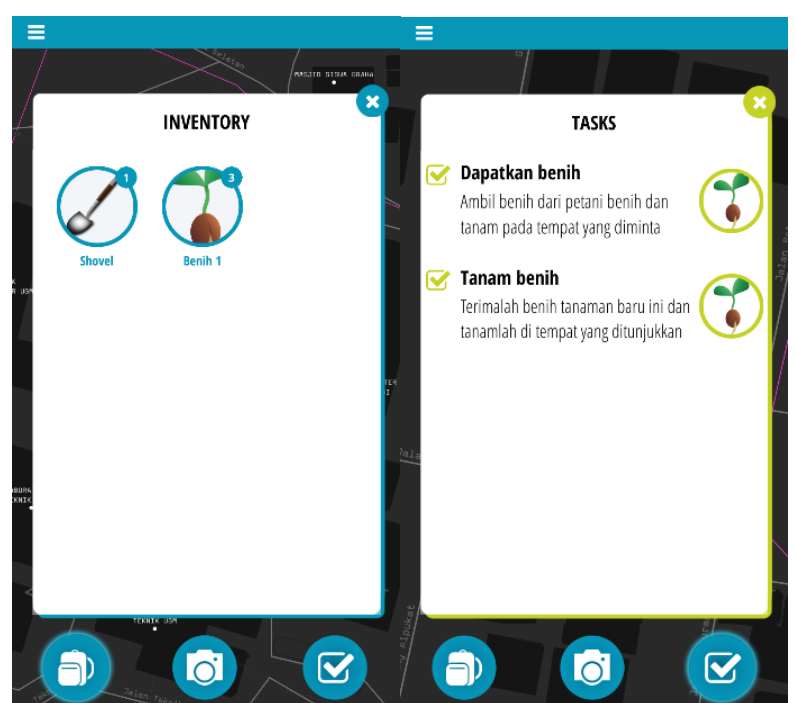

Figure 8. Inventory and Tasks Screen

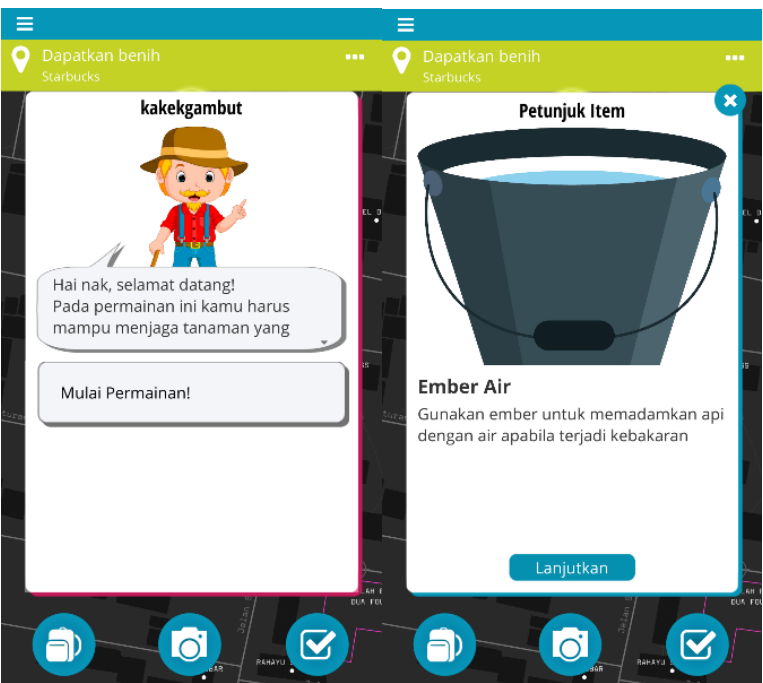

Figure 9. Character dialogue and clue screen

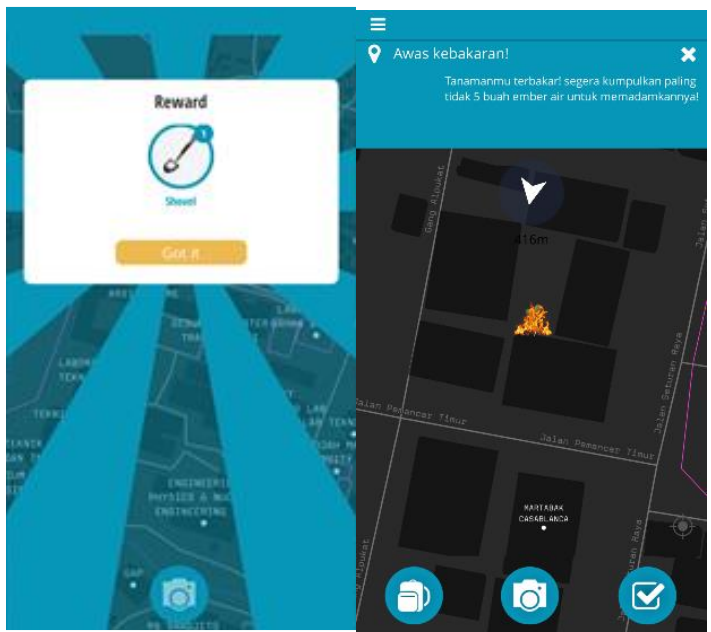

Figure 10. Reward and fire disaster screen 